\title{
Clinical and dermoscopic features of atypical abdominal brachytherapy-induced angiosarcoma
}

\author{
Beata Bergler-Czop, Karolina Hadasik, Ligia Brzezińska-Wcisło \\ Department of Dermatology, Medical University of Silesia, Katowice, Poland
}

Adv Dermatol Allergol 2016; XXXIII (4): 311-313

DOI: 10.5114/ada.2016.61609

Hemangiosarcomas are rare malignancies derived from blood vessel endothelium. In most cases, the origin of the tumor is difficult to be accurately determined due to poor cell differentiation. As far as skin is concerned, there are three clinical forms of the neoplasm:

1. Idiopathic hemangiosarcoma - most commonly located on the facial skin or scalp.

2. Hemangiosarcoma presented with limb edema in patients after mastectomy - referred to as Stewart-Treves syndrome.

3. Radiation induced angiosarcoma (arising in previously irradiated skin areas).

Angiosarcomas of deep soft and breast tissue in women were also reported. Recently an epithelioid angiosarcoma has been described as a rare aggressive variant [1-4].

Neoplasms, due to their clinical picture, are usually diagnosed late. Initially, the lesions appear as purple or red slow-growing patches. Nodules, which can undergo ulceration, appear over time.

Histopathological examination may reveal cell areas with polymorphic cells, numerous mitoses and irregular vascular channels. Some tumor cells have cytoplasmic vacuoles which correspond to the forming vessels. On the periphery, there are vascular channels with few atypical endothelial cells.

On dermoscopy, angiosarcoma is characterized by a combination of typical colors in vascular lesions - red, purple and blue. At the nodular part of the tumor, white lines can be detected. Radiation-induced angiosarcoma exhibits a more homogeneous pinkish-white pattern [5, 6].

Benign vascular lesions like rosacea, bruising, tumid lupus erythematosus or infections such as erysipelas and cellulitis are most often considered in differential diagnosis $[7,8]$.

The present case relates to a female patient with extensive angiosarcoma in the atypical location of the lower abdomen, which was treated locally over a long period of time, and dealt with as an erythematous spot of unknown etiology. The patient's history revealed brachytherapy due to endometrial cancer.

A 77-year-old patient exhibited her first skin lesions 5 months earlier; these suggested erythematous spots and were accompanied by severe itching. They were localized on the abdominal skin and were characterized by rapid growth. After 2 months, the lesions, bluish-violet at that time, progressed rapidly, and additional nodules and infiltrates appeared simultaneously. The patient history revealed brachytherapy due to endometrial cancer in 2002. The patient underwent a histopathological examination in an outpatient clinic in 2014 which revealed that the skin had numerous smaller blood vessels below the epidermis and within the dermis. The endothelium showed features of stimulation.

At the time of admission to the Department of Dermatology at Medical University of Silesia, lesions within the abdomen were well circumscribed from the surrounding skin. They reflected some bluish-purple infiltrates within which compacted dark-blue nodules were observed. The lesion dimensions were about $30 \times 20 \mathrm{~cm}$. The peripheral lymph nodes were not enlarged (Figure 1).

Laboratory results: erythrocyte sedimentation rate (ESR), complete blood count (CBC) with peripheral blood smear, iron levels, electrolytes, aspartate transaminase (AST), alanine transaminase (ALT), $\gamma$-glutamyltransferase (GGT), bilirubin, creatinine, urea, protein, protein, protein electrophoresis, creatine phosphokinase (CPK), aldolase, triglycerides, cholesterol, joint reactions (Latex-R, WaalerRose test, ASLO), general urinalysis and glucose levels were normal. Chest X-ray and abdominal ultrasound did not reveal any deviations from the norm. Dermoscopic image showed structureless red, purple-blue areas, white lines, yellowish clods on the periphery of some nodules

Address for correspondence: Karolina Hadasik MD, Department of Dermatology, Medical University of Silesia, 20/24 Francuska St, 40-027 Katowice, Poland, phone: +48 691197 602, e-mail: karolinahadasik@gmail.com Received: 26.08.2015, accepted: 27.10.2015. 


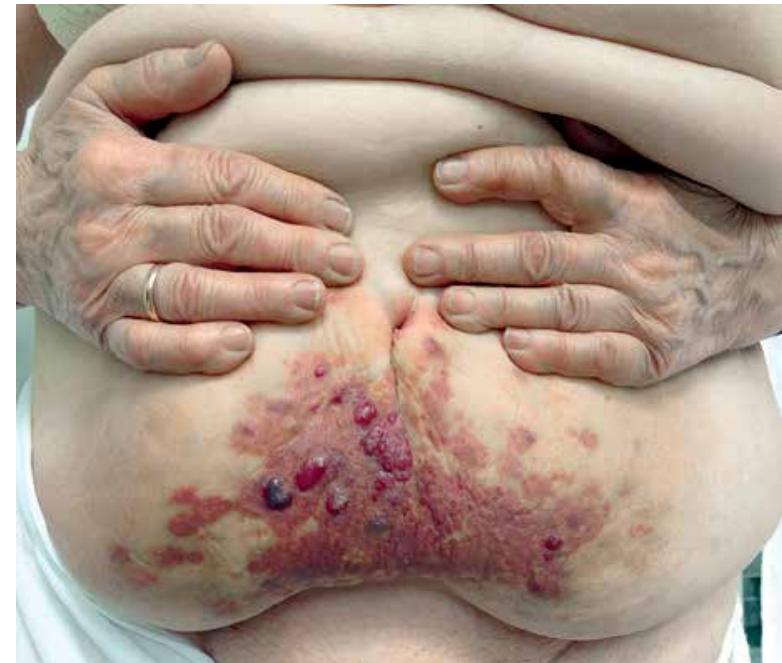

Figure 1. Lesions on the admission day - well-circumscribed bluish-purple infiltration with dark-blue nodules

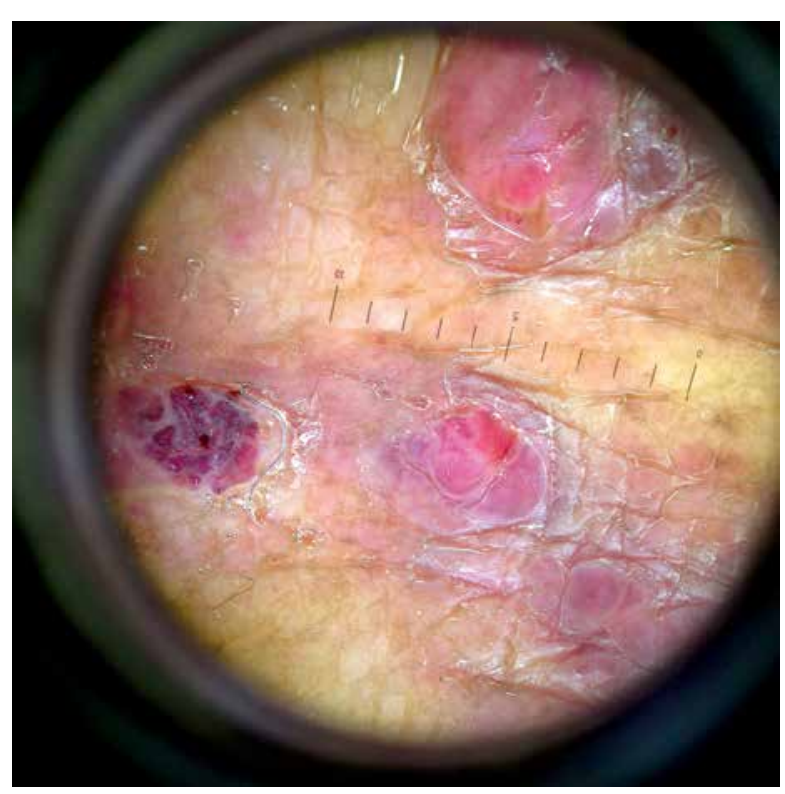

Figure 2. Dermoscopic image angiosarcoma - structureless red, purple-blue areas, white lines and structureless pinkish white areas and no solid pattern

and structureless pinkish white areas and no solid pattern (Figure 2).

Second histopathological examination confirmed the initial diagnosis: angiosarcoma. CD34+, Melan A-, LCA-, $\mathrm{Ki}-67+$ in about $10 \%$ of cells.

External therapy, which slightly relieved the patientreported pruritic ailments, was applied during the patient's stay at the clinic. The patient with histopathological diagnosis was referred to the Institute of Oncology for follow-up treatment. The therapy used palliative radiotherapy (the mean radiation dose was 70 Gy) - a few cycles of palliative chemotherapy with paclitaxel to render a slight improvement of the local condition. The patient was disqualified from surgical treatment. She currently remains under ongoing oncological observation for at least next 5 years.

Angiosarcoma is an aggressive malignant tumor of vascular endothelial cells or of lymphatic origin, whose clinical picture is variable and depends on the location. It occurs mainly in older white men. Its etiology is unknown. However, the effect of ionizing radiation is most frequently considered. The possible impact is also suspected in our patient's case.

Prognosis for cutaneous angiosarcoma, particularly in patients with tumors larger than $5 \mathrm{~cm}$ in diameter, is poor. The survival rate of 5 years is less than $30 \%$. The treatment guidelines are not clear. However, surgical wide excision treatment with subsequent radiotherapy is basic. Yet, local relapses occur in $80 \%$ of cases $[9,10]$.

Although total surgical resection with subsequent radiotherapy is considered as the therapeutic standard for angiosarcoma, an appropriate choice of safe and effective adjuvant treatment is significant for elderly patients with comorbidities. Liposomal doxorubicin combined with radiotherapy seems to be an effective and safe option. However, all these therapeutic methods are generally palliative in nature and may only prolong the patient's life, rarely offering permanent recovery. This type of therapy was also applied for our patient [11, 12].

Angiosarcomas are usually fast-spreading tumors with a strong tendency to metastasize to the lymph nodes. Currently, our patient does not show any spread of the neoplastic process. The most rapid metastases occur in angiosarcomas located within the head and neck.

Histologically, angiosarcoma has variable features. Well-differentiated lesions may be misinterpreted as angiomas or lymphangiomas, while poorly differentiated lesions may mimic melanomas. Therefore, the final diagnosis should be confirmed by immunological examination. In the present case, the examination indicated angiosarcoma CD34+, Melan A-, LCA-, Ki-67+ in about $10 \%$ of the cells $[13,14]$.

Hung et al. [15] compared the clinical and biological characteristics of angiosarcomas of unclear etiology and post-radiation angiosarcomas (as in our patient). Average time between radiation therapy and diagnosis of angiosarcoma was 11.9 years (so it was close to our case, i.e. 10 years). The patients with angiosarcomas after radiation therapy for tumors other than breast cancer had a shorter survival time than in the case of breast cancer radiotherapy.

The present case relates to a female patient with extensive angiosarcoma of the lower abdomen, which was treated locally over a long period of time. The patient's history revealed brachytherapy due to endometrial cancer. The dermoscopic pattern although not pathognomonic for a specific diagnosis, was highly suggestive of a malignant tumour. Unfortunately, our patient's prog- 
nosis is poor. She currently remains under ongoing oncological surveillance.

\section{Conflict of interest}

The authors declare no conflict of interest.

\section{References}

1. Düzgün S, Pekdemir I, Yılancı S, et al. A cutaneous angiosarcoma arising from the rhinophyma. Kulak Burun Bogaz Ihtis Derg 2013; 23: 344-7.

2. Cabete J, Lencastre A, Fidalgo A, et al. Postradiation cutaneous angiosarcoma of the breast: a diagnosis to keep in mind. Breast J 2014; 20: 89-90.

3. Mentzel T. Sarcomas of the skin in the elderly. Clin Dermatol 2011; 29: 80-90.

4. Wollina U, Hansel G, Schönlebe J, et al. Cutaneous angiosarcoma is a rare aggressive malignant vascular tumour of the skin. J Eur Acad Dermatol Venereol 2011; 25: 964-8.

5. De Giorgi V, Grazzini M, Rossari S, et al. Dermoscopy pattern of cutaneous angiosarcoma. Eur J Dermatol 2011; 21: 113-4.

6. Zalaudek I, Gomez-Moyano E, Landi C, et al. Clinical, dermoscopic and histopathological features of spontaneous scalp or face and radiotheraphy induced angiosarcoma. Australas J Dermatol 2013; 54: 201-7.

7. Ambujam S, Audhya M, Reddy A, Roy S. Cutaneous angiosarcoma of the head, neck, and face of the elderly in type 5 skin. J Cutan Aesthet Surg 2013; 6: 45-7.

8. Sharma $P$, Singh $H$, Singhal A, et al. Detection of recurrent cutaneous angiosarcoma of lower extremity with (18)f-fluorodeoxyglucose positron emission tomography-computed tomography: report of three cases. Indian I Dermatol 2013; 58: 242.

9. Kohen D, Dross P. Angiosarcoma of the scalp. Del Med J 2013; 85: 269-72.

10. Solari N, Spagnolo F, Ponte E, et al. Electrochemotherapy for the management of cutaneous and subcutaneous metastasis: a series of 39 patients treated with palliative intent. J Surg Oncol 2014; 109: 270-4.

11. Kim JE, Kim BJ, Kang H. A recurrent angiosarcoma isolated to the eyelid without the recurrence on the primary lesion of the forehead. Ann Dermatol 2014; 26: 231-5.

12. Fujita M, Endo Y, Fujisawa A, et al. An alternative in taxane-resistant cutaneous angiosarcoma. Eur I Dermatol 2014; 24: 267-8

13. Iga N, Endo Y, Fujisawa A, et al. Two cases of cutaneous angiosarcoma developed after breast cancer surgery. Case Rep Dermatol 2012; 4: 247-9.

14. Sharma S, Deshmukh AD, Bal MM, et al. Angiosarcoma of the scalp associated with xeroderma pigmentosum. Indian J Med Paediatr Oncol 2012; 33: 126-9.

15. Hung J, Hiniker SM, Lucas DR, et al. Sporadic versus radiation-associated angiosarcoma: a comparative clinicopathologic and molecular analysis of 48 cases. Sarcoma 2013; 2013: 798403. 